\title{
Multiple recurrences of HSV-1 on right lower buttock
}

\author{
Surav Man Sakya BS, Judy Park DeWitt BS, Ashley Sturgeon MD
}

\begin{abstract}
Herpes simplex virus type 1 (HSV-1) is a common localized viral infection that affects many individuals in the general population. HSV-1 infection most commonly presents on the face and lips. In contrast, HSV-2 most commonly appears in a boxer distribution in the anogenital region, which can include the buttocks. We report a healthy 28-year-old Asian woman with multiple reoccurrences of grouped vesicles with an erythematous base on her right inferior medial buttock. On viral serologic testing, the etiological agent was HSV-1, not HSV-2. This case highlights the presentation of HSV-1, not HSV-2, in this location.
\end{abstract}

Keywords: HSV-1, HSV-2, buttock, recurrent infection

\section{INTRODUCTION}

There are two types of Herpes simplex virus, Herpes simplex type 1 (HSV-1) and Herpes simplex virus type 2 (HSV-2), both of which infect and remain latent in sensory ganglia. ${ }^{1}$ Initially, the patterns of clinical presentation for both viruses are similar and indistinguishable. Both HSV types present as grouped vesicles with an erythematous base and an umbilication of the center. In their course, the vesicles usually re-epithelialize and heal with crusting. Transmission and common locations of clinical presentation vary between the two types. ${ }^{2} \mathrm{HSV}-1$, a common virus associated with cold sores, typically presents in the oral areas, including the lips. ${ }^{3} \mathrm{HSV}-1$ frequently occurs in childhood and is transmitted via respiratory secretions and saliva. HSV-2, commonly referred to as genital herpes, has a high incidence of infection in the genital areas. ${ }^{4}$ Transmission of HSV-2 occurs perinatally and through sexual contact.

Corresponding author: Surav Man Sakya Contact Information: ssakya@pennstatehealth.psu.edu DOI: 10.12746/swrccc.v7i27.492
Reoccurrence of HSV-1 is more common than HSV-2 reoccurrence, and the most frequent reoccurrence of HSV-1 is in the oral-facial region. ${ }^{5,6}$ Physical or psychological factors, such as stress, can cause reoccurrence of HSV infections. These infections are more likely to reoccur in the same location as the primary site of infection. However, auto-inoculation of HSV can occur on any location on the skin. ${ }^{7}$ A study of HSV distribution of 4437 typed isolates showed that $71 \%$ of isolates in the anogenital region, including the buttocks, were of HSV-2 virus, and $29 \%$ were of HSV-1 virus. ${ }^{8}$ The distribution of HSV-1 in the buttock region is uncommon. Here, we present a case of HSV-1 infection in the right inferior medial buttock.

\section{CASE}

A 28-year-old, Asian woman who immigrated to the United States at the age of ten presented with a case of HSV-1 infection. At the age of 11, she experienced high fever which manifested as blisters on the lips and on the right inferior medial buttock. She denies sexual trauma or abuse. She tested positive for HSV-1 IgG on serology but negative for HSV-2 IgG. Over the years, she continued to have 

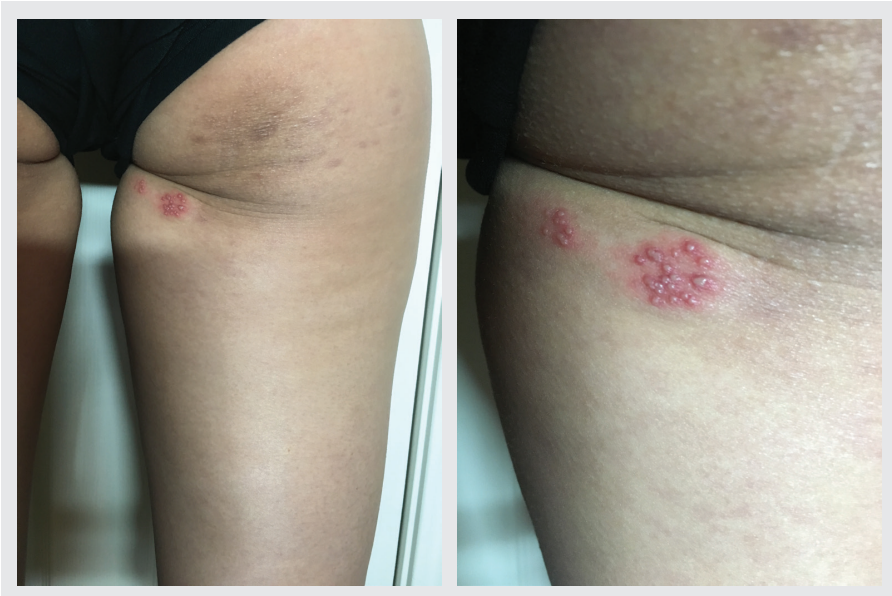

Figure 1A and B. A 28-year-old, Asian woman with a recurrent HSV-1 infection in the right inferior medial buttock showing two grouped vesicles with an erythematous base. The patient gave permission for the use of Figures 1 and 2.

recurrence of the blisters on the lips and buttock. Her lip blisters occur 2 or 3 times per year and can be treated with rest, hydration, and 10\% decanol topically. The blisters on the buttock appear in times of extensive stress, including immigration and new jobs. Since the first breakout at the age of 11, she has had similar blisters of lesser severity at ages 17 and 25. Each occurrence resolved with rest within a week. The blisters on the lips and buttock never occurred concurrently other than the first time at the age of 11 . Her current reactivation consists of blisters that were painful, non-pruritic vesicles with an erythematous base closely grouped in two clusters (Figure 1A and B). The first cluster of vesicles is $1 \mathrm{~cm}$ in diameter, and the second cluster measures $1.5 \mathrm{~cm}$ (Figure 2A and 2B). The patient reported resolution of the symptoms within a week with docosanol ointment and rest.

\section{Discussion}

HSV-1 and HSV-2 share similar clinical presentations, but the pattern of distribution for each type of virus is unique. HSV-1 typically presents in children/adolescents as grouped vesicles with an

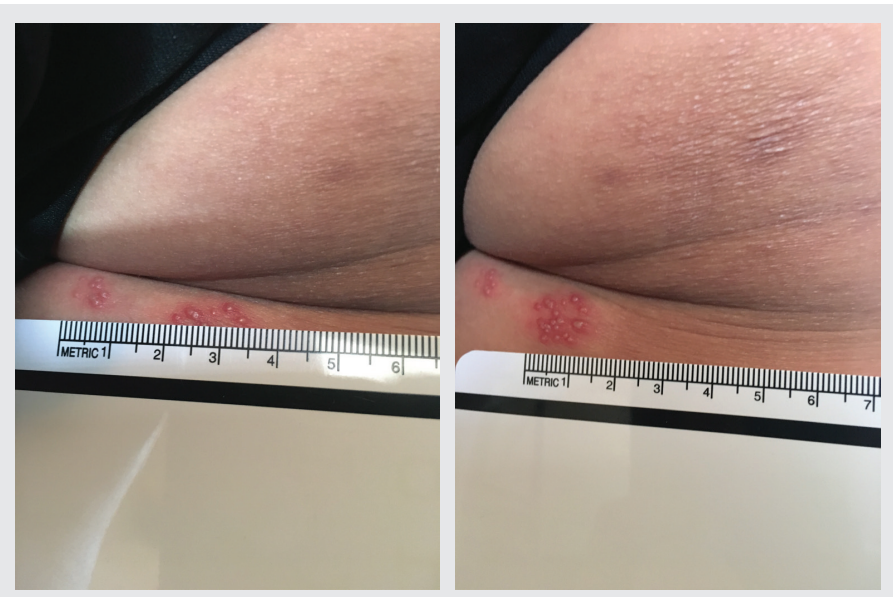

Figure 2A and B. Recurrent HSV-1 infection in the right inferior medial buttock with (A) grouped vesicles measuring $1 \mathrm{~cm}$ in diameter and (B) grouped vesicles measuring $1.5 \mathrm{~cm}$.

erythematous base above the waist, while HSV-2 usually follows a boxer distribution in the genital region. Recurrent vesicular eruptions similar to the ones presented on this patient's buttock have been frequently misdiagnosed as Herpes zoster virus because the vesicles appear in a dermatomal "zosteriform" pattern. However, literature reports indicate that the vesicles in the genital region are due to HSV-2 and not Herpes zoster virus. ${ }^{8}$ The importance of this case report is the development of HSV-1 in the buttock location. One hypothesis is that the patient's multiple reoccurrences of HSV-1 infection in that region developed due to auto-inoculation of the virus at the age of 11 . Medical literature suggests several reasons for occurrences of HSV-1, including stress and immunosuppression. In our case, multiple recurrences of HSV-1 were precipitated by major personal stressors. In vivo studies have shown that a patient's own strain of HSV can cause reactivation at another site. ${ }^{9}$ Therefore, our patient could have transmitted the viral particles from the oral cavity to the buttock through direct inoculation from her fingertips. Although it is unclear whether or not the patient's HSV-1 in the buttock was primary or secondary infection, this case highlights that HSV-1 can occur in this atypical location. 
Article citation: Sakya SM, DeWitt JP, Sturgeon A. Multiple recurrences of HSV-1 on right lower buttock. The Southwest Respiratory and Critical Care Chronicles 2019;7(27):72-74

From: The Department of Dermatology (JPDW, AS) at Texas Tech University Health Sciences Center, Lubbock, Texas; and Penn State College of Medicine (SMS), Hershey, PA

Submitted: 9/1/2018

Accepted: $12 / 18 / 2018$

Reviewer: Mark Lacy MD

Conflicts of interest: none

This work is licensed under a Creative Commons Attribution-ShareAlike 4.0 International License.

\section{REFERENCES}

1. Smith J, Robinson N. Age-specific prevalence of infection with Herpes simplex virus types 2 and 1: a global review. The J Infectious Diseases 2002;186(S1). doi:10.1086/343739

2. Aral SO, Over M, Manhart L, et al. Disease control priorities in developing countries. New York, NY: Oxford University Press. 2006;315.
3. Marks JG, Miller JJ. Lookingbill and Marks Principles of Dermatology. Philadelphia: Elsevier. 2019;138-140.

4. Beauman JG. (2005). Genital herpes: a review. American Family Physician 2005;72(8):1527-1534.

5. Freeman ML, Sheridan BS, Bonneau RH, et al. Psychological stress compromises cd8 T cell control of latent Herpes simplex virus type 1 infections. The J Immunology 2007; 179(1):322-328. doi:10.4049/jimmunol. 179.1.322

6. Löwhagen G, Tunbäck P, Bergström T. Proportion of Herpes simplex virus (HSV) type 1 and type 2 among genital and extragenital HSV Isolates. Acta Dermato-Venereologica 2002;82(2):118-120. doi:10.1080/00015550252948158

7. Bader C, Crumpacker CS, Schnipper LE, et al. The natural history of recurrent facial-oral infection with Herpes simplex virus. J Infectious Diseases 1978;138(6):897-965. doi:10.1093/ infdis/138.6.897

8. Heskel NS, Hanifin JM. Recurrent Herpes zoster: an unproved entity? J Am Acad Dermatol 1984;10(3):486-90.

9. Ribes JA, Steele AD, Seabolt JP, et al. Six-year study of the incidence of herpes in genital and nongenital cultures in a Central Kentucky Medical Center patient population. J Clinical Microbiology 2001;39(9):3321-3325. doi:10.1128/jcm.39.9. $3321-3325.200$ 